\title{
ERRATUM
}

\section{Ethnic comparison of the association of undiagnosed diabetes with obesity}

R Nyamdorj, J Pitkäniemi, J Tuomilehto, N Hammar, CDA Stehouwer, TH Lam, A Ramachandran, ED Janus, V Mohan, S Söderberg, T Laatikainen, R Gabriel and Q Qiao for the DECODA and DECODE Study Groups

International Journal of Obesity (2010) 34, 597; doi:10.1038/ijo.2009.248

Correction to: International Journal of Obesity (2010) 34, 332-339; doi:10.1038/ijo.2009.225; published online 3 November 2009

Since the above publication the authors have noticed errors in the list of affiliations.

Dr Gabriel R's right affiliation is: Clinical Epidemiology and Research Unit, Hospital Universitario La Paz, Madrid, Spain.
Söderberg S's complete affiliation is: Department of Public Health and Clinical Medicine, Cardiology, University of Umeå, Umeå, Sweden.

The typesetters would like to apologize for this mistake. 